Do tilt-in-space wheelchairs increase occupational engagement: a critical literature review

Harrand, J

http://hdl.handle.net/10026.1/5302

10.3109/17483107.2014.932021

Disability and Rehabilitation: Assistive Technology

Informa UK Limited

All content in PEARL is protected by copyright law. Author manuscripts are made available in accordance with publisher policies. Please cite only the published version using the details provided on the item record or document. In the absence of an open licence (e.g. Creative Commons), permissions for further reuse of content should be sought from the publisher or author. 


\section{Benefits of walking and solo experiences in UK wild places}

This paper examines human-nature interaction and how therapeutic this relationship is by investigating the efficacy of structured outdoor experience. Two walking and solo experience (WSE's) explored university students' (aged 20 - 43 years) perceptions of walking through and being with nature. The first was a five day journey ( $=4 ; 3$ females and 1 male) and the second ( $\mathrm{n}=5 ; 3$ females and 2 males) took place over two weekends, with a two week interval inbetween. Pre- and post-experience interviews, journal writing, group discussions and a nine month follow-up interview were used to collect data and thematic analysis was applied. Both WSEs were considered together in a thematic analysis (Braun \& Clarke, 2006), as well as comparisons made between the two, in order to evaluate implications for practice.

Benefits of the WSE that contributed to a general sense of well-being were: 1) gaining a sense of freedom and escape; 2) gaining a sense of awareness and sensitivity to one's environment and its influence 3) gaining confidence in being able to cope and take action; 4) gaining a sense of perspective on and appreciation for life. Furthermore, the meaning participants formed in relation to their environment before, during and after the WSE, and the activity within that environment, played a role in their sense of well-being and in their motivations to re-access nature in other places. As one of few UK-based studies on outdoor structured experiences, findings suggest that WSEs are a cost effective way to give rise to powerful, beneficial and durable experiences. 


\section{INTRODUCTION:}

In England there is considerable evidence of people's relationship with nature suggesting its value for their mental health and well-being. The Monitor of Engagement with the Natural Environment (Natural England, 2014) is a large survey showing that people in England visit the countryside, green spaces in towns and cities, and the coast most, enjoying watching wildlife, volunteering to help protect the natural environment, with $38.9 \%$ of the population making visits to natural environments at a total of 751.8 million. The benefits of contact with nature are diverse, with a wealth of literature arguing for its role in human health and well-being, as well as spiritual health, all of which advocate its healing or restorative properties (Pretty et al., 2007). Restorative perspectives have been dominated by Ulrich's (1984) psychophysiological stress reduction framework and Kaplan and Kaplan's (1989) attention restoration theory (ART, Hartig, 2008).

Based on ART, Kaplan (1995) believed that directed attention and cognitive functioning could be restored if time is spent in 'restorative environments' (e.g. Felsten, 2009). Kaplan (1995) has argued that properties of an attention restoring experience are: 'being away', moving away or taking a mental break from activities that are attentionally demanding and that cause fatigue; 'fascination', an effortless and compelling form of involuntary attention and intrinsic interest in the situation; 'extent', sufficient scope to sustain interaction for a period of time without boredom; and 'compatibility', a perceived fit between the person's informational needs, intended goal and what the environment provides. Such properties were found to be dependent on the kind and quality of the environment, involvement with the environment, and frequency and duration. Indeed, Berman et al. (2008) noted that natural environments provoke involuntary attention because these environments are "rich with inherently fascinating stimuli," (p. 1207) without demanding directed attention.

Regular exposure to natural environments has been found by a number of studies to counteract attentional fatigue in healthy adults. Early evidence was of psychological benefits from wilderness experiences (Kaplan \& Talbot, 1983) and less intense exposures to natural environments, such as a view from a window (Ulrich, 1984). More focused studies on effects of natural environments on cognitive function also showed improved attention and mental restoration (e.g. Ottosson \& Grahn, 2005).

Further support for the benefit of contact with nature comes from the environmental self-regulation hypothesis: that one's environment provides invaluable information according to which one assesses emotions; people use environmental strategies as a process to "maintain a balance between pleasant and unpleasant emotions and a coherent experience of self' (Korpela et al., 2001, p. 387). Disconnectedness with nature, therefore, has been understood as a 'dysregulation' between person and environment. Dysregulation reflects difficulties in awareness and understanding of the interrelatedness and interconnectedness between people and the natural world (Gratz \& Roemer, 2004). This suggests that people have some innate connections with their environment; that environment is more than a setting in which things exist and where happenings occur but rather something that we are deeply connected to.

The reported growth in mental health problems in the UK - 1 in 4 people in the UK experience mental health problems (Mental Health Foundation, 2014) and most commonly experiencing a combination of depression and anxiety - means that it is essential for people's mental health and wellbeing to understand and harness the potential benefits of 
nature and structured outdoor programmes. There are three strands to this umbrella term; structured outdoor recreation programmes (participation is for fitness and/or pleasure), structured outdoor experiential programmes (participation can be for pleasure and/or skills and confidence building and challenge) and outdoor therapy programmes (participation has a very specific therapeutic purpose / aim for the client and provider). Each of these three types of outdoor programmes are all experiential in kind, but progressively increase in their likelihood of resulting in therapeutic outcomes, as the level of intervention or therapeutic intent increases i.e. recreational has the lowest therapeutic intent and outdoor therapy has the highest. The degree of challenge and adventure (unfamiliar settings and managing risk instigate learning and impelling experiences) that each programme includes also have an important impact on participant's experiences as psychological and physical challenges both support growth, learning, developing skills, leadership and to some degree (depending on the extend of therapeutic intent) healing (Friese et al., 1998).

To investigate the potential benefits of human-nature interaction a structured outdoor experiential programme was custom-designed for UK conditions: the walking and solo experience (WSE). This form of programme was chosen because the researcher was not a trained therapist and therefore could not deliver outdoor therapy, but wanted to investigate a programme with greater therapeutic intent than recreational programmes. This paper discusses the qualitative findings from two WSE's.

\section{METHODOLOGY:}

Following ethical clearance from the York St John University Ethics committee, a grounded theory approach (Charmaz, 2006) informed the design of the studies. This approach encompassed the following: the need to get out into the field to discover what is going on; highlighting the complexity and variability of phenomena and of human action; persons acting on the basis of meaning; the understanding that meaning is defined and redefined through interaction (Corbin \& Strauss, 2008); a subjectivist epistemology that looks at how individuals view their situations; and acknowledging that any resulting theory is an interpretation (Charmaz, 2006).

The participants in both studies were volunteers, students recruited from Counselling degree programmes, and two participants took part in both. In study one the four participants (by pseudonym) were: one male, Joe (aged 39) and three females, Kit (aged 22), Sam (aged 37), and Alex (aged 42). Two students in this group knew each other well (Kit and Joe). Study two had five participants, with Joe from study one acting as an assistant guide (helping the researcher with group safety): two males, Dannie (aged 23) and Leslie (aged 36), and three females, Nina (aged 20), Sarah (aged 23), and Alex (aged 43).

Data were collected from multiple sources so that each participant had opportunity to express their experiences in a method that suited them, and the situation, best. Participants were each interviewed before and after their experience, so that a comparison could be made before and after the WSE, and diaries (from which they selected material for inclusion) and group discussions were used to capture (more in-the-moment) experiences during the WSE. Using multiple data collection methods provided a rich data set that captured the 'whole' experience of preparing for and doing a WSE, and thus avoided 'partial' data collection and exploration. A nine month follow-up interview was also conducted to assess the temporal effects of such an experience and any change in perspectives (if any). Interviews and 
group discussions were audio recorded which were then transcribed and coded, highlighting parts of text and labelling them with 'tags' in NVivo, and analysed by Thematic Analysis (TA) (Braun \& Clarke, 2006).

\section{Data Collection: Walking and Solo Experience phases}

Developed in wilder UK places, in this instance Northumberland (study one) and North Nidderdale (Study 2), the WSE consisted of a five day journey involving participants in wild camping, moving from one location to another (walking through), and a solo experience (sitting within) comprising a 34 - 36 hour time of isolation in nature (no electronic equipment or books, but participants could keep a journal and sketch).

Phases (exploration, journey and solo) were used to describe the structure of, and identify transitions in, the WSE. The phases primarily identified the transition from landscape to landscape (urban to natural) and between activities ('walking through' and 'sitting within'). Phases were thus intended to facilitate the experiences and emotional and physical journeys of the participants. The purpose of the exploration phase was to gradually and safely ease participants physically and psychologically into the unfamiliar natural landscape. Thus walking was relatively short in distance and duration. The journey phase intended to provide an opportunity for participants to move through the landscape, to carry all the food, shelter and belongings they needed. It was during journeying that the aspect of adventure and challenge was most likely to occur (depending on the individual's prior experience). Challenging experiences were also possible during the solo phase, but it was important for this phase to provide a more intensely psychological challenge e.g. reflection and introspection. During the solo experience participants were asked not to go beyond 30 metres of their tent so as not to disturb other participants and encourage participants to sit within the environment.

Study one took place in September over a five day period (from a Sunday to a Friday). The WSE started at a bunkhouse that provided basic and comfortable accommodation. Participants stayed at the bunkhouse for the first two nights to enable rest after a long journey and to gently expose participants to the landscape, allowing for preparations for the journey phase and camping. Study two took place at the end of August and beginning of September. The leadership structure was similar to that in study one but the WSE was spread over two weekends and had a two week interval, enabling the WSE to maintain its length of five days, but offering perhaps a more affordable and accessible experience (this was an important consideration if WSEs are to be offered in collaboration with a mental health service in the future). This changed structure was an opportunity to examine the differences between the two models, to further investigate the transitions between landscapes (e.g. wild place and everyday life) and to consider how the intervention could be offered by services in a manageable and affordable way.

Ethical considerations

The affective objectives of the WSE in both studies were to provide a memorable and powerful experience that would make an impression on participants and support personal growth, also known as enrichment (Crisp, 1996). The exploration, journey and solo elements of the WSE, as well as the choice in reflective tool (e.g. data collection method), helped achieve enrichment but it was important to ensure that the location of the WSE itself was safe. 
Considerations about the terrain were important for promoting an enjoyable, manageable experience, and ensuring that the level was within everyone's capability e.g. that no participant was put under any undue stress or danger. The location was therefore risk assessed before each study and the researcher attained a Mountain Leader and first aid qualification before the first study commenced so as to able to lead the WSE. Each WSE also had an assistant guide to ensure that, in the event of an accident, an experienced person always remained with the group. My leadership and conduct could also be observed, which helped create and ensure a safe and ethical experience for participants.

\section{Reflexivity}

The combination of ethical and reflexive practices is considered to improve the rigour and trustworthiness of qualitative inquiry (Chiovitti \& Piran, 2003; Willig, 2008). Within the current research I acknowledge that my beliefs, experiences and interests influenced my decision making and actions and thus shaped the research. My experiences of journeying in 'wild' landscapes, on my own and with groups, led me to conduct this research and influenced my ideas about peoples' behaviour in nature. These experiences have provided me with the knowledge, skill and confidence to create and lead my own WSE which inevitably changes the dynamics of the research process and relationship that can be formed with participants and the research itself: sometimes it made it easier to build rapport and at other times it did not. I acknowledge that research findings are my own experiential account of the research, which is contingent, provisional, partial, restricted, and local (Miller et al., 2008); I included wholeheartedly my own subjectivity in the research.

\section{FINDINGS:}

The themes in the findings that illustrated the benefits of the WSE were: 1) gaining a sense of freedom and escape; 2) gaining a sense of awareness and sensitivity to one's environment and its influence 3) gaining confidence in being able to cope and take action; 4) gaining a sense of perspective on and appreciation for life. Collectively these contributed to a general sense of wellbeing and, generally, there was very little difference between the two groups.

\section{Gaining a sense of freedom and escape}

A sense of freedom and escape was mainly facilitated by the natural landscape and associated with getting away, being away from everyday life, responsibilities, pressure and obligation:

\section{Nina, journal, study two}

It feels like this camping is (.) because we are away from 'reality' in a sense + home comforts then it's a much simpler way and I feel more calm because of this but when I'm home it just feels so much more complicated and I'm constantly thinking.

\section{Dannie, follow-up interview, study two}


[...] I did enjoy being away from (.) sort of (.) everyday pressures and complications really (.) if I'm honest (.) erm (.) like like uni' and work and paying bills and sort of that kind of eventually just went out of my mind completely (3) ... I felt (.) sort of more freedom from those kind of pressures

\section{Sam, follow-up interview, study one}

$[\ldots]$ being both a student and a mum and running a house I think it was really just total time out for me when sometimes you can do something for yourself at home but it's probably an hour (.) you know if you go do something like tai-chi or go out on your bike it's a little snap shot and then you're back into that whereas that was a longer period so it was really time to totally chill out [...] I was just doing it for me (.) not to prove (.) anything to anybody else

Feeling freedom and 'being' was therefore intimately linked with daily activities and expectations and the ability to relinquish these, contributing to gaining a sense of perspective and appreciation. Many studies report benefits of being away from everyday pressures (Heinztman, 2009; Hinds, 2011; Patterson et al., 1998) and from being somewhere with a sense of remoteness (Glaspell et al., 2003), but those studies do not provide such clear examples of freedom and meanings associated with freedom.

Some of the features that led to feelings of freedom and escape also interrupted and distracted, however. Memories of struggling with unwanted distractions from, and interruptions to, their experiences were strongly recollected in post-experience data and the nine month follow-up. These were: physical challenges (e.g. dealing with the terrain and injuries), social challenges and pressures or dynamics (e.g. dealing with rules and conflict), and psychological challenges such as responsibilities, everyday life and 'other people':

\section{Leslie, post-experience interview, study two}

Well sometimes (.) I felt a bit isolated (.) erm (2) it was like when I was struggling through the rough ground and (.) well just when I was struggling I suppose in general (.) I kind of felt a bit isolated (.) erm (.) sort of like when you're lagging behind and that $[\ldots]$ but in the second weekend (.) I quite enjoyed that you know when we were walking up and I sat on that rock (.) and I said like you's walk on I knew where I were (.) I kind of enjoyed that (.) and I enjoyed that bit of isolation

\section{Sarah, follow-up interview, study two}

Interviewer: What was it like to have a routine almost imposed on you?

Sarah: That would be the hardest part I think (.) like (.) sticking to a schedule (.) cos I don't do that (.) I just kind of do what I fancy [...] no it was more like social (.) pressure in that (.) I like to do my own thing but at the same time I'm really really reluctant to break any rules (.) not that there were any rules do you know what I mean? like I don't like 


\section{Joe, journal, study one}

I found the morning of the $24 \mathrm{hr}$ difficult in the sense I had unwanted thoughts come up, and negative feelings from past and current stuff [...] being out in the wilderness seemed to intensify the feelings as there seemed no distractions.

\section{Alex, post-experience interview, Study one}

$[\ldots]$ I wouldn't have classed it as remote (.) [...] and I think it spoilt it because of the walk where the people were there (2) the fellas where they were having their cheese sandwiches (2) that kinda spoilt it (2.5) [...] it kind of blew the whole thing up and I thought you know that's really spoilt my erm (3) my (2.5) kinda like fantasy image of where we were

Challenges thus spanned the physical, social and psychological domains, supporting previous research (Patterson et al., 1998; Sklar, 2005). Those challenges that were met and overcome were fondly remembered in contrast to those that were harder to overcome. Additionally, the felt benefits motivated a number of participants to go on further walking trips or sitting by a local river. This implies that they had the confidence to re-access the experience, despite any apprehensions and challenges regarding ability, experience or skill levels prior to, during or after the WSE (reported in journals and pre- and post-experience interviews). To my knowledge, this motivation to re-access the experiences has not been documented in the outdoor experience literature.

Gaining a sense of awareness and sensitivity to one's environment and its influence

This theme refers to participant experiences of embodiment and to meaning created by interaction with artefacts. Participants' experiences of embodiment were memorable and relate to instances where participants gained an increased sense of self-awareness, whilst also feeling relieved from pressures to perform socially. For example, Alex described being able to relinquish her social 'mask' and just be, and caring less about her physical appearance:

\section{Alex, journal, study two}

In the wild place I don't have to wear a mask - in the solo phase I can just be me - and I am so looking forward to it. [...] Oh it will be so good to get away from what's going on in the world, (pretend) it's not happening. I am so looking forward to not having to spend time making sure my hair's ok and not worrying about what my clothes look like, or what I look like. [...] Here there were no distractions, I won't get hurt from another person, I am safe in this place. I don't have to put on an act - a mask (2) I can just be me with no distractions. 
This recognition of personal value supports research by Autry (2001), but Autry observed it in relation to outdoor therapy. The above experiences of a renewed sense of value may also support ideas about walking and solo elements acting like a cleansing phase and fostered by being away from the familiar (Russell \& Farnum, 2004).

Characteristically, these experiences were most often experienced and strongly felt during the solo phase, but also seemed to transfer to their daily lives. For example, some participants cared less about how they looked or smelt shortly after the WSE:

\section{Joe, focus group, study one}

[...] smelliness (.) not during but when we got back [sniffs loudly] back to the railway station (.) like I don't smell (.) like everyone else does

Whether this extended further than short-term meaning is unclear however, as a disconnect between experience and transferability of valued aspects into everyday life is not unusual (Autry (2001). Despite this uncertainty, participant's experiences of the WSE prompted reflection on, and subsequently greater awareness of, the influence of one's environment, particularly cultural influences. The beneficial experience of embodiment and its longterm impact supports other work on outdoor experiences (e.g. Hennigan, 2010), including increases in self-awareness in natural environments (Kaplan, 1995); and that personal growth was a benefit of outdoor experiences (Nanschild, 1997; Sklar, 2005). Bobilya et al. (2009) found that meaningful life events like these were particularly related to the solo phase of wilderness experiences.

Gaining confidence in being able to cope and take action

This theme was reportedly an enduring benefit. Confidence was seen to build as a consequence of overcoming fear, doubt or uncertainty about ability, and dealing with situations. Below, Sam reports her experience of a steep hill that took her back to past challenges that demanded her physical and psychological strength - her experience of cancer. The challenges reminded her of her strength and resilience:

\section{Sam, journal, study one}

There were times on the walk especially on the climbs when I felt like it was a struggle and was slightly beginning to doubt my ability. When I had made it to the top though I did feel better

Alex reported changes in thoughts during the solo and a sense of being able to cope alone.

\section{Alex, post-experience interview, study one}

$[\ldots]$ it just really opened my mind you know (2) I can be on my own (2) can survive on my own 
Kit reported the benefit of having time to reflect on relationships and family issues: when she returned home from the WSE she had a much clearer and determined idea about what to do and subsequently carried out the plans she had made during the solo to re-establish a relationship with a family member:

\section{Kit, journal, study one}

When I got back I was so happy and eager to do as much as I could in a day. I've not had such a positive mentality for so long to this extreme. [...] Since the time away I've known exactly what I've wanted and needed to do with my current relationships, family and work, when before I was a little stuck.

\section{Kit, follow-up, study one}

Yeah I mean I sort of spend time on the farm, like with my sister, erm and there's rarely a time where I don't see her at all cos now I make more of an effort cos I wanted to see my nephews as well. And before I were sort of too scared to approach her about it, so it worked out ok

The experiences are also seen to transfer into everyday life in the ways that participants re-accessed nature and aspects of the WSE. Further positive action that was taken after the WSE, as a result of a gained sense of confidence and competence, was Alex's reports of self-led walking trips to the Lake District and the Highlands. Her reports were shared joyfully and with pride during her follow-up interview:

\section{Alex, follow-up interview, study two}

We went up Scafell Pike erm and camped (.) yeah for two nights just on a field with no one [...] so yeah that was the first time and the second one we've just been up to Scotland (.) erm we camped at Delaware forest and then at Ben Nevis and then went up to isle of Skye camped there for a night

These and other achievements were recollected and related to confidence building: for example dealing with, letting go of control and getting to the top. Re-accessing nature and aspects of the WSE were thus a positive consequence from gaining a sense of confidence. Given the experiences of the participants in this study, beneficial experiences from a WSE seem to be enduring. Development of confidence and self-esteem through structured outdoor programmes has also been shown by other studies (Barton \& Pretty, 2010; Hattie et al., 1997; Pretty et al., 2007).

Gaining a sense of perspective on and appreciation for life

This theme relates to participants' experiences of valuing 'the little things', home comforts, and 'simple' things like running water:

\section{Dannie, post-experience interview, study two}

[...] being able to just come for a shower and that erm (.) it makes you appreciate (.) those small things and that's another great thing about it (.) it makes you really appreciate the little things that you've got (.) that are 
(.) not necessities $[\ldots]$ and everything basically that's in the house is a luxury (.) but you don't have to carry everything about back that's in the house $[\ldots]$ you can get clean (.) and put on some new clothes go out you know you don't have to carry all your clothes about

Sarah also reported, in her post-experience interview, a change in the way she viewed life, noticing nature more in everyday life whilst walking in the city and going into nature (such as a river bank) when feeling anxious, gaining great pleasure and reflection time in watching ducklings swim in the water, being in green spaces and noticing nature. The solo experience was particularly memorable for her and her realisation that she could 'be still'. It was during her time alone that she concluded that she had found her 'outlet' - nature - to reduce her anxiety:

\section{Sarah, post-experience interview, study two}

I think what I'll really keep which is really lovely (.) is that that realisation that I have the potential to stand still [...] it's nice that there's an outlet that I do feel dead calm (.) really good (.) because I think it's something to try and incorporate into my life (.) that will be really healthy (.) and that's really positive $[\ldots]$ it's that therapeutic thing that just makes you feel better

This reduction in anxiety and stress has also been found by Pearson and Smith (1986), suggesting that people use nature as an environmental strategy for self-regulation. More generally it illustrates a sense of wellbeing gained after, and as a consequence of, experiences during the WSE. A male participant from study two explicitly mentioned an increased sense of 'wellbeing' when he returned back to everyday life, finding the transition to impact on his 'usual' behaviour and routine and that he had intense feelings of still being connected to nature:

\section{Joe, journal, study one}

[...] Coming back I noticed smells more strongly such as perfume from passers-by and sense of wellbeing, it also struck me I had not even thought about what was happening in the news and when I did begin to watch it I just turn it off (not like me) I felt a bit more sensitive to the negative reports on it. I had some wine with my dinner but felt I did not really want it! (another not like me) Later I switched the TV off as I found the noise distracting and just sat in the silence and by candlelight. I still have a feeling of being connected to the outdoors for the moment...

This evidence supports various studies reporting that structured outdoor experiences enhance wellbeing (Hinds, 2011; Nicholls, 2008). The most profound reported experiences in the current study occurred during the solo phase but few studies (e.g. Nicholls, 2008) have related increased wellbeing to 'being still'; this warrants further investigation. Furthermore, though the general benefits of time alone are well documented (Angell, 1994; Knapp and Smith, 2005; Nicholls, 2009), the parameters need further study. 
These data support the inclusion of short or extended periods of time alone but participants' preferences for the length of solo varied in the data. It is thus important to negotiate an appropriate length with the participants, whilst also balancing it with the aim of the programme or experience. One of the participants sums up the benefits of the WSE:

\section{Alex, post-experience interview, study one}

Interviewer: $\quad[\ldots]$ how would you describe the programme to another person who knew nothing about the scheme?

Alex: oh ok (.) well that they should do it [laughter] (.) that it's a freeing experience (.) you know (2) telling them about their environment (.) and everything that goes on erm (3) just that it is a really (.) really freeing really freeing you know (.) and you get a real awareness if you [...] so (3) personal growth [...] and gaining confidence

Overall, these examples suggest that WSEs - and natural environments more generally - can give rise to powerful and durable experiences. It is important to be aware that these beneficial and meaningful features of participants' experiences overlap and influence aspects of each other. The activity of walking through and being in nature alone, without distractions of modern life (i.e. solo phase), were meaningful activities to participants in an environment that provided wonderment - nature. More research on WSEs is needed however, in order to identify active features and common benefits that are generalizable to inform a mental health promotion strategy that can be made available to a wider group of people. Nevertheless, the current research shows that the WSEs contributed to a greater sense of wellbeing, that meaning-making is an important process in fostering wellbeing and motivation to re-access nature, and that WSEs are a cost effective approach that are also useful for hard to reach populations, such as males.

\section{IMPLICATIONS FOR POLICY}

With reports stating mental health problems in the UK have increased (Mental Health Foundation, 2014) and the National Obesity Observatory (NOO) highlighting the scale of the health problems associated with obesity (Cavill \& Roberts, 2011), it is important to consider many ways of reducing ill-health. In 2002 the Department of Culture, Media and Sport, indicated a 10\% increase in adult physical activity would benefit England by $£ 5000$ million per year, saving 6000 lives, and the NOO stated that more research is needed to identify the associations people have with aesthetic features of the natural environment and the benefits of them. It is essential, therefore, to understand and harness the potential benefits of contact with nature for people's mental health and wellbeing, utilising nature as prevention and intervention, whilst also improving policy and increasing commitments to future research.

The current findings suggest that guided exposure to wilder places in the UK can lead some people to reexperience nature and to being more active in their quest to do so. By protecting these wilder landscapes and supporting access to them it will likely help increase physical activity in everyday life as people learn the value of it and being near nature. Additionally, the long-term changes in awareness and attitudes towards nature shown in the current study also 
suggests that, with more comprehensive support of WSE style approaches, environmental consciousness may be raised more widely: Aspects like spending time alone with nature can be accessed without any support from a leader being thus more accessible and inclusive; Opportunities and possibilities for transformations and actions that support sustainability outcomes would be fostered by providing more support for further research into practice; and getting the policy right and supporting various methods and enterprises that support people in connecting with the outdoors will likely help improve health and wellbeing.

Though there have been developments in policy, particularly around service-led and a personalisation agenda, giving greater emphasis to people being part of treatment rather than having it imposed upon them is also imperative. Broad policy support may be seen to exist, but more evidence is needed to demonstrate the translation of policy into practice and therefore further empirical research is needed to identify specific ways of interacting and connecting with nature. Such efforts may provide the momentum needed to implement these ideas and methods in practice. For example, MacKerron and Mourato (2013) provide a new line of evidence on the links between nature and wellbeing, piloting new innovative research methods and informing the UK National Ecosystem Assessment (NEA). However, "little is known about the mechanisms that are important for delivering these benefits" (Keniger et al., 2013, p. 913) and therefore evidence should address how to optimise and harness the benefits of wild spaces, and support people to access them. These efforts, and the appeal of a perhaps less stigmatised 'outdoor' approach to therapy/support, may also increase the likelihood of reaching men experiencing mental health problems - a repeatedly 'hard to reach' population (Mental Health Foundation, 2014). Furthermore, considering the cognitive benefits of outdoor approaches, they may complement and enhance the effectiveness of cognitive behavioural therapy (CBT). CBT is the most widelyresearched and evidenced of all the counselling approaches - effective in treating mental health problems like depression, anxiety, obsessive compulsive disorder and post-traumatic stress - but often the quality of the therapeutic relationship determines the effectiveness of CBT (Hofmann et al., 2012). Engaging with clients, especially males and young people, in the outdoors in an enjoyable and active way is a useful way to forge good relationships and thus can be important for success in CBT. Further investigation into the design, implementation and cost of structured outdoor experiences, and how best to optimise their benefits, positive environmental consequences and cognitive-therapeutic applications, is therefore needed.

As well as safeguarding people's wellbeing, natural environments also need protection. The lack of policy to protect natural environments is widely evident. In the guidelines on physical activity and environment they mention only recommendations for access to open spaces, such as parks, coastal rivers and forest pathways (NICE, 2008), which although beneficial, does not cover the protection of more remote natural environments. Neither does it provide for more creative kinds of access and support - something more than just transport provision. Policy also does not recognise the important role of the meaning associated with activity and experiences in natural environments. Recent NICE (2012) guidelines on ways of promoting walking and cycling as forms of travel or recreation, state nothing of the influence and beneficial role of meanings associated with places and space. The meaning participants formed in relation to their environment before, during and after the WSE and the activity within that environment played a role in their sense of wellbeing and in their motivations to re-access nature in other places and in other ways and thus warrants 
a greater emphasis in Policy. Furthermore, how the outdoor space is perceived influences usage, concerns for personal safety and ease of access to natural environments (Gladwell et al., 2013), which has consequences to protection, access and sustainability agendas previously stated. Consequently, a more ecological or holistic approach in policy is thus required in the existing paradigms for public health and natural environment (Pretty et al., 2003). Natural environments need to be protected from becoming merely a commodity for society but at the same time access should be improved.

\section{REFERENCES:}

Angell, J. (1994). The Wilderness Solo. Women \& Therapy, 15(3-4), 85-99.

Autry, C. E. (2001). Adventure Therapy with Girls At-Risk: Responses to Outdoor Experiential Activities. Therapeutic Recreation Journal, 35(4), 289-306.

Barton, J., \& Pretty, J. (2010). What is the best dose of nature and green exercise for improving mental health? A multistudy analysis. Environmental Science \& Technology, 44(10), 3947-3955.

Berman, M. G., Jonides, J., \& Kaplan, S. (2008). The cognitive benefits of interacting with nature. Psychological Science, 19(12), 1207-1212.

Bobilya, A. J., Akey, L., \& Mitchell Jr, D. (2009). Outcomes of a spiritually focused wilderness orientation program. Journal of Experiential Education, 31(3): 440-443.

Braun, V. \& Clarke, V. (2006). Using thematic analysis in psychology. Qualitative Research in Psychology, 3 (2), $77-$ 101 .

Campbell, L. (2010). 'Go somewhere, do something'. How students responded to the opportunity to complete an unstructured, five-day, wilderness solo in the Cantabrian Mountains, Northern Spain. Journal of Adventure Education \& Outdoor Learning, 10(1): 33-49.

Cavill, N., \& Roberts, K. (2011). Sources of data for investigating the influence of the environment on physical activity and diet. Oxford: National Obesity Observatory.

Daniel, B. (2005). The life significance of a wilderness solo experience. In C. Knapp and T. Smith (Eds.), Exploring the Power of Solo, Silence and Solitude (pp. 85-102), Boulder: Association for Experiential Education.

Department of Environment, Food, and Rural Affairs (DEFRA). (2011). White Paper: The natural Choice: securing the value of nature. Retrieved from: http://www.official-documents.gov.uk/document/cm80/8082/8082.pdf

Felsten, G. (2009). Where to take a study break on the college campus: An attention restoration theory perspective. Journal of Environmental Psychology, 29 (1), 160-167.

Friese, G. T., Pittman, T., \& Hendee, J. C., (1998). Studies of the use of Wilderness for personal growth, therapy, education, and leadership development: An annotation and evaluation. Retrieved from: http://www.webpages.uidaho.edu/wrc/Publications/big1indx.pdf.

Gladwell et al. (2013) The great outdoors: how a green exercise environment can benefit all. Extreme Physiology \& Medicine, 2(3) Retrieved September 29, 2014, from: http://www.extremephysiolmed.com/content/2/1/3

Glaspell, B., Watson, A., Kneeshaw, K., \& Pendergrast, D. (2003). Selecting indicators and understanding their role in wilderness experience stewardship at Gates of the Arctic National Park and Preserve. In The George Wright Forum(Vol. 20, No. 3, pp. 59-71)

Gratz, K. L., \& Roemer, L. (2004). Multidimensional assessment of emotion regulation and dysregulation: Development, factor structure, and initial validation of the Difficulties in Emotion Regulation Scale. Journal of Psychopathology and Behavioral Assessment, 36, 41-54.

Hartig, T. (2008). Green space, psychological restoration, and health inequality.The Lancet, 372(9650), 1614-1615. 
Hattie, J., Marsh, H. W., Neill, J. T., \& Richards, G. E. (1997). Adventure education and Outward Bound: Out-of-class experiences that make a lasting difference. Review of Educational Research, 67(1), 43-87.

Heintzman, P. (2009). Men's wilderness experience and spirituality: Further explorations. In Proceedings of the 2007 Northeastern Recreation Research Symposium (pp. 55-59).

Hennigan, K. (2010). Therapeutic potential of time in nature: Implications for body image in women. Ecopsychology, 2(3), 135-140

Hinds, J. (2011) Exploring the psychological rewards of a wilderness experience: An interpretive phenomenological analysis. The Humanistic Psychologist, 39, 189-205

Hofmann, S. G., Asnaani, A., Vonk, I. J., Sawyer, A. T., \& Fang, A. (2012). The efficacy of cognitive behavioral therapy: a review of meta-analyses. Cognitive therapy and research, 36(5), 427-440.

Kaplan, S. (1995). The restorative benefits of nature: toward an integrative framework. The Journal of Environmental Psychology, 16, 169-182.

Kaplan, S., \& Talbot, J. F. (1983). Psychological benefits of a wilderness experience. In Behavior and the natural environment (pp. 163-203). US: Springer.

Keniger, L. et al., (2013). What are the benefits of interacting with nature? International Journal of Environmental Research and Public Health, 10, 913-935.

Knapp, C. E., \& Smith, T. E. (eds.) (2005). Exploring the power of solo, silence, and solitude. Boulder, CO: Association for Experiential Education, pp. 3-18.

Korpela, K., Hartig, T., Kaiser, F., \& Fuhrer, U. (2001). Restorative experience and selfregulation in favorite places. Environment and Behavior, 33, 572-589

MacKerron, G. \& Mourato, S. (2013, in press). Happiness is greater in natural environments. Global Environmental Change. Retrieved from: http://dx.doi.org/10.1016/j.gloenvcha.2013.03.010

Mental Health Foundation (2014). Retrieved September 5, 2014, from: http://www.mentalhealth.org.uk/helpinformation/mental-health-statistics/

Nanschild, D. (1997). Women's Perceptions and Experiences of Outdoor Recreation. In T. Gray and B. Hayllar (eds), Catalysts for change: $10^{\text {th }}$ National Outdoor Education Conference Proceedings, Sydney

Natural England, N. (2005). England Leisure Visits-Report of the 2005 Survey. Cheltenham: Natural England. Retrieved from: http://www.naturalengland. org. uk/leisure/recreation/dayvisits05. pdf Leisure in the landscape, 289.

Natural England (2014). " Monitor of Engagement with the Natural Environment

The national survey on people and the natural environment", available at:

https://www.gov.uk/government/uploads/system/uploads/attachment_data/file/425520/mene-reportdecember2014-february2015.pdf (accessed 24 March 2014)

NICE (2008). Physical activity and the environment,. NICE public health guidance 8. Retrieved from: http//www.guidance.nice.org.uk/ph8

NICE (2012). Walking and cycling: local measures to promote walking and cycling as forms of travel or recreation. NICE public health guidance, 41. Retrieved from: http://www.nice.org.uk/nicemedia/live/13975/61629/61629.pdf

Nicholls, V.E. (2008). Busy doing nothing: research the phenomenon of "quiet time" in a challenge-based Wilderness Therapy. Unpublished thesis, Faculty of Education: University of Wollongong.

Nicholls, V. (2009). Quiet Time: A sense of solitude. Outdoor education research and theory: critical reflections, new directions, Fourth International Outdoor Education Research Conference, Beechworth, Victoria AU. Retrieved from: http://www.latrobe.edu.au/education/downloads/2009_conference_nicholls.pdf

Ottosson, J. \& Grahn, P. (2005). A comparison of leisure time spent in a garden with leisure time spent indoors: on measures of restoration in residents in geriatric care. Landscape Research, 30(1), 23-55. 
Patterson, M. E., Williams, D. R., Watson, A. E., \& Roggenbuck, J. R. (1998). An hermeneutic approach to studying the nature of wilderness experiences. Journal of Leisure Research, 30, 423-452.

Pearson, M., \& Smith, D. (1986). Debriefing in Experience-Based Learning. Simulation/games for learning, 16(4), $155-72$.

Pretty, J., Griffin, M., Sellens, M. \& Pretty, C. (2003). Green exercise: Complementary roles of nature exercise and diet in physical and emotional well-being and implications for public health policy. CES Occasional Paper 2003-1, University of Essex.

Pretty, J. N., Peacock, J., Hine, R., Sellens, M., South, N., \& Griffin, M. (2007). Green exercise in the UK countryside: Effects on health and psychological well-being, and implications for policy and planning. Journal of Environmental Planning and Management, 50(2), 211-231.

Russell, K. C. \& Farnum, J. (2004). A concurrent model of the wilderness therapy process. Journal of Adventure Education and Outdoor Learning, 4(1), 39-55.

Sklar, S. L. (2005). Positive youth development: The case of a wilderness challenge intervention (Doctoral dissertation, University of Florida).

Ulrich, R. S. (1984). View through a window may influence recovery from surgery. Science, 224(4647), 420-421. 